\title{
ECDC publishes updated evidence-based guidance for chlamydia prevention and control and makes latest chlamydia figures available online through interactive Surveillance Atlas
}

O Mardh ${ }^{1}$, A Amato-Gauci ${ }^{1}$

1. European Centre for Disease Prevention and Control (ECDC), Stockholm, Sweden

Correspondence: Otilia Mardh (Otilia.mardh@ecdc.europa.eu)

Citation style for this article:

Mardh O, Amato-Gauci A. ECDC publishes updated evidence-based guidance for chlamydia prevention and control and makes latest chlamydia figures available online through interactive Surveillance Atlas. Euro Surveill. 2016;21(10):pii=30157. DOI: http://dx.doi.org/10.2807/1560-7917.ES.2016.21.10.30157

Article submitted on 28 February 2016 / accepted on 10 March 2016 / published on 10 March 2016

On 7 March 2016, an updated version of the 'Guidance on chlamydia control in Europe' was published on the European Centre for Disease Prevention and Control (ECDC) website. As the previous version, published in 2009 [1], the newly released document aims at supporting policymakers and national programme coordinators in the European Union (EU) and European Economic Area (EEA) countries in developing, implementing and improving their chlamydia control strategies in an evidence-based manner.

Also on 7 March, the most recent surveillance data on chlamydia were made available in the interactive ECDC Surveillance Atlas of Infectious Diseases [2]. In 2014, there were 396,128 cases of chlamydia infections officially reported from 26 EU/EEA countries with young people between 15 and 24 years of age accounting for $63 \%$ of all reported cases.

Since the 2009 publication of Chlamydia control in Europe' guidance, the evidence base for informing control policies has advanced and now shows that offering chlamydia testing to young women (under 25 years of age) can reduce the risk of developing pelvic inflammatory disease. To date, however, there is as yet no clear evidence that population-based interventions like widespread testing or screening programmes can reduce the prevalence of infections or the incidence of long-term reproductive tract complications [3].

The recently published guidance provides options for EU/EEA countries to consider as their minimum level of prevention and control activities:

- a national strategy or plan for control of sexually transmitted infections (including chlamydia),
- provision of primary prevention interventions to atrisk individuals and groups,

- evidence-based chlamydia case management guidelines that address criteria for testing, diagnostic methods, treatment, partner notification and reporting of cases,

- improved systems for the surveillance of diagnosed infections, and

- an evaluation plan for the strategy.

The scaling-up to widespread testing or screening programmes should be considered on the basis of individual benefit of those tested and if sufficient resources are available and suitable monitoring and evaluation is in place.

The policy options presented in this guidance should be interpreted and applied according to clinical, epidemiological, healthcare and resource environments which differ across the EU/EEA countries [4].

\section{References}

1. European Centre for Disease Prevention and Control. Chlamydia control in Europe. Stockholm: ECDC, 2009. Available from: http://ecdc.europa.eu/en/publications/ Publications/0906_GUI_Chlamydia_Control_in_Europe.pdf

2. European Centre for Disease Prevention and Control. (ECDC) ECDC Surveillance Atlas of Infectious Diseases. Stockholm: ECDC, 2016. Available from: http://atlas.ecdc.europa.eu/ public/index.aspx?Dataset $=251$

3. European Centre for Disease Prevention and Control (ECDC). Chlamydia control in Europe: literature review. Stockholm ECDC, 2014. Available from: http://ecdc.europa.eu/en/ publications/Publications/chlamydia-control-europe.pdf

4. European Centre for Disease Prevention and Control.

Chlamydia control in Europe: a survey of Member States (2012). Stockholm ECDC, 2014. Available from: http://ecdc.europa. eu/en/publications/Publications/chlamydia-control-surveyeurope-2012.pdf 


\section{License and copyright}

This is an open-access article distributed under the terms of the Creative Commons Attribution (CC BY 4.0) Licence. You may share and adapt the material, but must give appropriate credit to the source, provide a link to the licence, and indicate if changes were made.

This article is copyright of the European Centre for Disease Prevention and Control, 2016. 